\title{
Palmar Vitiligo Associated with Graves' Disease
}

\author{
Yosuke Sasaki ${ }^{1}$, Mitsuyo Kinjo ${ }^{2}$, Rita Lynn McGill $^{3}$ and Hitoshi Miyasato ${ }^{2}$
}

Key words: palmar vitiligo, Graves' disease, NALP1 inflammasomes, polyglandular autoimmune syndrome type 2

(Intern Med 52: 2001-2002, 2013)

(DOI: 10.2169/internalmedicine.52.0685)

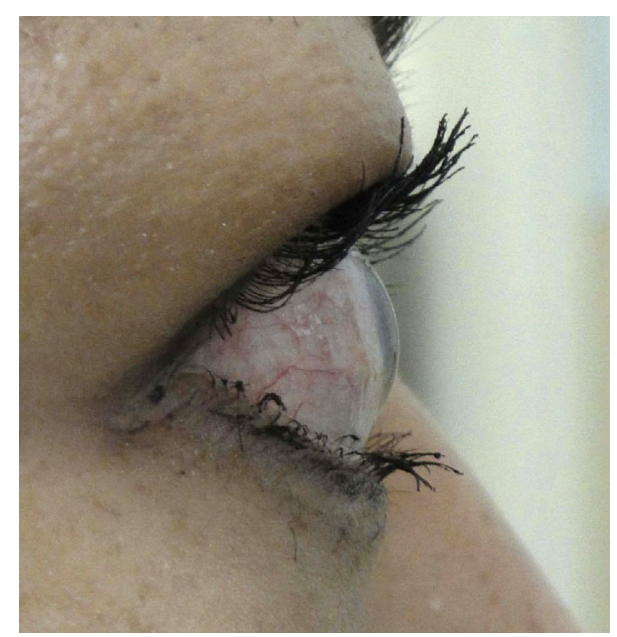

Picture 1.

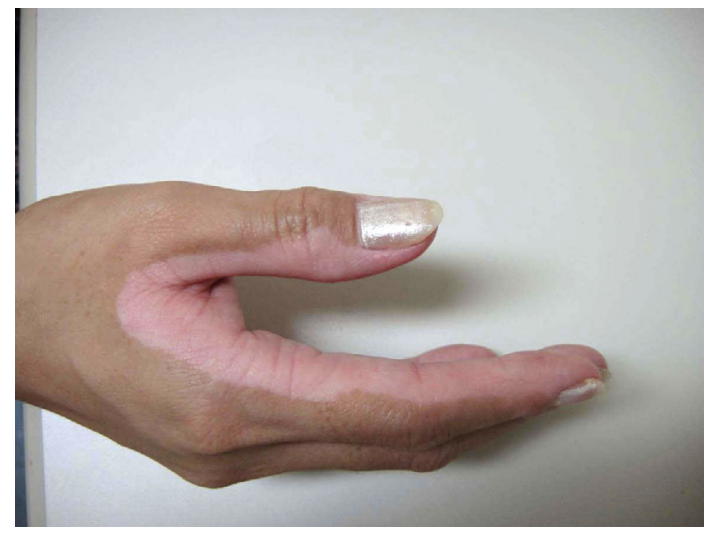

Picture 3.

A 30-year-old previously healthy Japanese woman presented with tachycardia, exophthalmos (Picture 1), diffuse painless goiter (Picture 2) and well-demarcated palmar vitiligo that had developed a few months earlier (Picture 3). Graves' disease was diagnosed based on the following: ele-

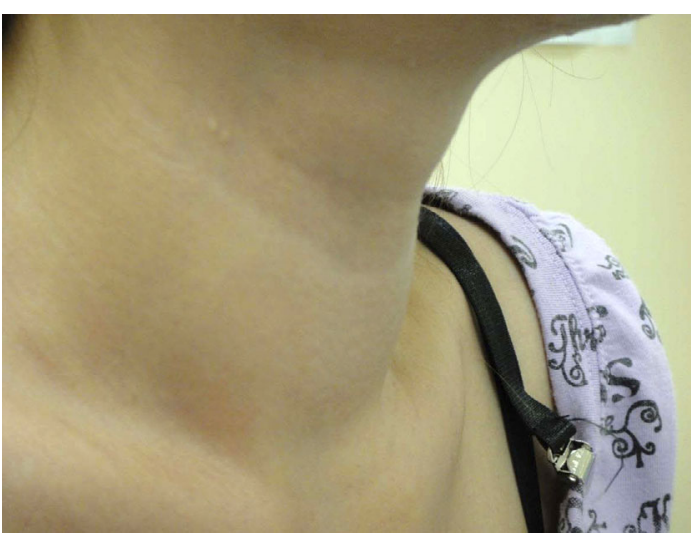

Picture 2.

vated free T4, a suppressed thyrotropin level and positivity for anti-thyroid receptor antibodies. Vitiligo has been previously reported as a symptom of polyglandular autoimmune syndrome type 2 , and the condition has also been associated with autoimmune diseases such as Graves' disease, adrenal insufficiency, pernicious anemia, lupus and diabetes. Recently, a genetic analysis has enabled the identification of certain shared susceptibility genes that may cause these diseases, such as the genetic polymorphisms that are located in the locus of NALP1 inflammasomes on chromosome 17 (1). Despite the lack of genetic confirmation, the simultaneity of the onset of both vitiligo and Graves' disease suggests that they may develop as expressions of a shared susceptibility gene. An awareness of this association may aid in the early diagnosis of other latently coexisting and potentially fatal autoimmune diseases (2).

The authors state that they have no Conflict of Interest (COI).

\section{References}

1. Jin Y, Mailloux CM, Gowan K, et al. NALP1 in vitiligo-associated

${ }^{1}$ Okinawa Yaeyama Hospital, Japan, ${ }^{2}$ Okinawa Chubu Hospital, Japan and ${ }^{3}$ Allegheny General Hospital, USA Received for publication April 2, 2013; Accepted for publication April 21, 2013

Correspondence to Dr. Yosuke Sasaki, pqrstbb@yahoo.co.jp 
Intern Med 52: 2001-2002, 2013 DOI: 10.2169/internalmedicine.52.0685

multiple autoimmune disease. N Engl J Med 356: 1216-1225, 2007.

2. Neufeld M, Maclaren NK, Blizzard RM. Two types of autoim- mune Addison's disease associated with different polyglandular autoimmune (PGA) syndromes. Medicine (Baltimore) 60: 355, 1981.

(C) 2013 The Japanese Society of Internal Medicine http://www.naika.or.jp/imonline/index.html 